\title{
A view of Liliequist's membrane through an endoscope- A case report.
}

\author{
Dr. Aaijaz Ahmed Khan ${ }^{1}$, Dr. ZulIzharMohd. Ismail ${ }^{1}$, Prof HillolKantipal ${ }^{2}$, Dr. \\ Shamim Ahmed Khan ${ }^{3}$ \\ Department of Anatomy ${ }^{2,}$ Departmentof Neuroscience and ${ }^{3}$ Department of ORL, School of Medical Sciences, \\ UniversitiSains Malaysia.
}

\begin{abstract}
Liliequist's membrane is an important surgical landmark in various neurosurgical operations. The structure of the Liliequist's membrane, as reported in the literature, varies considerably. Most of the anatomic studies of Liliequest's membrane have been reported following removal of both the frontal lobes. This report presents the image of Liliequist's membrane as viewed endoscopically from a retrosigmiod, posterior cranial fossa approach, in a formalin fixed cadaver. The images provided, define its anatomic features and boundaries, as well as its relationship with surrounding neurovascular structures.
\end{abstract}

Key words - Liliequist membrane, endoscope, retrosigmoid, posterior cranial fossa

\section{Introduction}

Liliequist's membrane is a complex and variable arachnoidal structure. It may be absent but when present, is either a single membrane or two-leaved membrane. Various studies have attempted to define its structure, boundaries and relationships. It is an important structure when approaching theinterpeduncular fossa or for ventriculostomyfor hydrocephalous, as not opening it may cause the failure of endoscopic third ventriculostomy (Buxton et al. 1998). Therefore it is necessary to do a proper pre-operativeMagnetic Resonance imaging for presence or absence of Liliequist membrane or other membranes, located in the prepontine cistern (Yad Ram Yadav et al. 2012). In the present study we tried to study theLiliequist's membrane endoscopically through the posterior cranial fossa approach to define its boundaries and relationships.

\section{Material \& Methods}

Two formalin-fixed cadaveric heads were subjected to endoscopic exploration of Liliequist's membrane through a posterolateral endoscopic access to the retroinfundibular fossa and interpeduncular cistern via a superomedial extension of the retrosigmoid approach transgressing the tentorial hiatus. The study was performed using Richard Wolff $2.0 \mathrm{~mm}$ and $5.0 \mathrm{~mm}$ diameter rigid endoscopes at viewing angles of $0^{\circ}$ and $30^{\circ}$. In one of the cadavers the Liliequist's membrane was exposed in its entirety (Fig.1).

\section{Results}

In our specimen Liliequist's membrane was a single membrane that arose anteriorly from the arachnoid covering the dorsum sellae, posterior clinoid processes, posterior petroclinoidal folds, and adjacent tentorial edge (Fig.1). A posterosuperior free border was seen extending between the two oculomotor nerves in front of the Basilar artery.After removing the Liliequist's membrane posterior cerebral artery, posterior communicating artery, optic chiasma and pituitary stalk werevisualized in the interpeduncular fossa(Fig.2).

\section{Discussion}

In 1956, Liliequistconfirmedradiographically a membrane that was located between the interpeduncular and chiasmatic cisterns using pneumoencephalography. This membrane was also clearly identified on his anatomic dissections with a free border in front of the Basilar artery. Zhang and An (2000) described Liliequist's membrane as a "double-layer fold" of the arachnoid mater, continuous with the arachnoid mater covering the tentorium. Froelich SC et al. (2008) described it as a complex and variable structure of the basal cisterns. More recently Song-tao Qi et al (2011) reinvestigated ambient cisternsystem and its related arachnoid membranes. They stated that theperimesencephalic membrane is a set of inner arachnoid membranes surrounding the midbrain at the level of the tentorialincisura and the ambient cistern is supratentorialcistern system, which is located above the level of the tentorial edge and perimesencephalic membrane

Liliequist's membrane's endoscopic appearance varies and it is not always seen during ventriculostomy. It may be because theLiliequist's membrane and the third ventricular floor are opened simultaneously in most instances, therefore it cannot be identified as a separate membrane. But in the present study it is clearly evident (fig. 1 and 
2) with its free border in front of the basilar artery. Yasargil MG et al. (1976), describing the basal cisterns as a "road map" to access vascular or neoplastic lesions stated that Liliequist's membrane "stretches like a curtain from one mesial temporal surface to another". Matsuno et al. (1988) identified two distinct membranous sheets: the first, a diencephalic membrane, which extends upward and attaches to the diencephalon posterior to the mammillary bodies, separates the interpeduncular and chiasmaticcisterns systems; and the second, a mesencephalic membrane, which extends backward and attaches along the pontomesencephalic junction, separates the interpeduncular and prepontine cisterns. Brasil and Schneide (1993) described Liliequist's membrane as three continuous intercisternal walls: right and left carotid-interpeduncular walls and a central chiasmatic-interpeduncular wall. Lü and Zhu (2005) identified a pair of diencephalic-mesencephalic membranes that join the diencephalic and mesencephalic leaf with a posterior free border between the attachment to the lateral margin of themammillary body and the attachment to the mesencephalic leaf.

\section{FIGURES}

Fig.-1

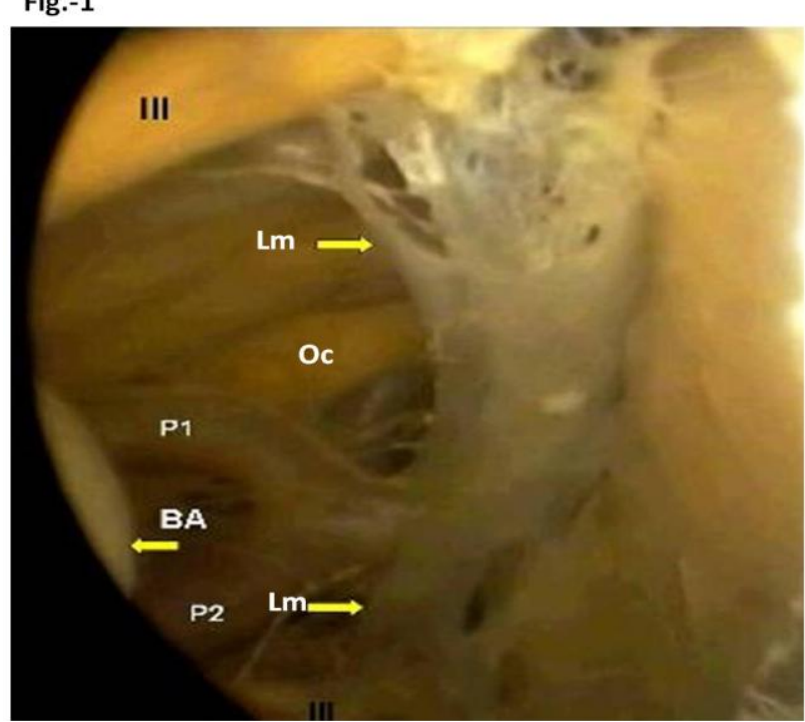

Fig- 1 Lillequestmembranee

Lm- Lliequist membrane, P1 \&P2- Posterior cerebral artery, IIIn- Occulomator nerve, PC- Posterior communicating artery, Oc - Optic chiasma, BA- Basilar artery

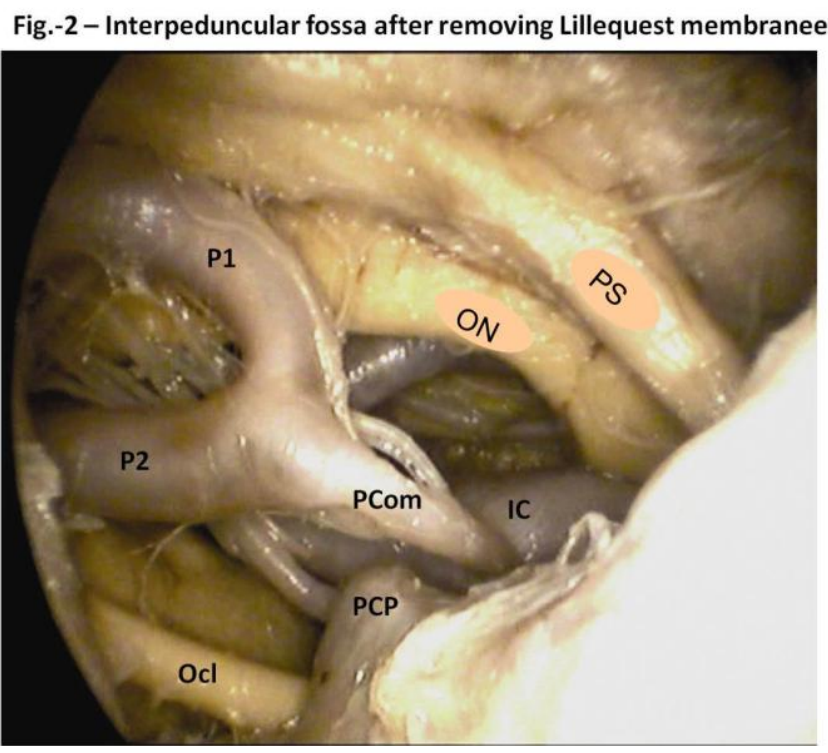

Note- Please put this photograph

Fig.-2Interpeduncular fossa after removing Lillequestmembranee

P1 \&P2- posterior cerebral artery, Ocl- Occulomator nerve, PCom- Posterior communicating artery, $\mathrm{ON}$ - Opticnerve, IC- Internal carotid artery, PCP- posterior clinoid process, PS- pituitary stalk 


\section{Conclusion}

It is necessory to understand the anatomy of Liliequist's membrane as it is important, particularly to improve current and forthcoming microsurgical and endoscopic neurosurgical procedures. It also acts as an important surgical landmark in various interpeduncular fossa neurosurgeries and in the pathophysiology of suprasellar arachnoid cysts and perimesencephalic hemorrhage.

\section{Acknowledgment}

I am very grateful to the people who are instrumental in the preparation of this manuscript. Firstly I would like to thanks Dr. Asma Hassan, Head of the department of anatomy for permitting us to do endoscopic studies on cadavers available in the department. I am also thankful to anatomy technologist En. MohdHarisal, En. MohdEidiAzhary and Haji Shukri Abdullah for offering help in cadaveric dissection and photography.

\section{References}

[1]. Binitie O, Williams B, Case CP. A suprasellar subarachnoid pouch: Aetiological considerations. J NeurolNeurosurg Psychiatry 47, 1984, 1066-1074.

[2]. Brasil AV, Schneider FL. Anatomy of Liliequist's membrane. Neurosurgery 32, 1993, 956-961.

[3]. Buxton N, Vloeberghs M, Punt J. Liliequist's membrane in minimally invasive endoscopic neurosurgery. ClinAnat 11,1998, 187190.

[4]. Froelich SC, Abdel Aziz K, Cohen P, van Loveren HR, Keller JT. Microsurgical and endoscopic anatomy of Liliequist's membrane: a complex and variable structure of the basal cisterns. Neurosurg 63(1) Operative Neurosurgery Supplement 1, 2008, ONS1-ONS9.

[5]. Liliequist B. The anatomy of the subarachnoid cisterns. ActaRadiol 46, 1956, 61-71

[6]. Liliequist B. The subarachnoid cisterns: An anatomic and roentgenologic study. ActaRadiolSuppl 185, 1959, 1-108.

[7]. Lu J, Zhu X. Microsurgical anatomy of the interpeduncular cistern and related arachnoid membranes. J Neurosurg 103, 2005, 337341.

[8]. Matsuno H, Rhoton AL Jr, Peace D. Microsurgical anatomy of the posterior fossa cisterns. Neurosurgery 23, 1988, 58-80.

[9]. Song-tao Qi, Jun Fan, Xi-an Zhang and Jun Pan. Reinvestigation of the ambient cistern and its related arachnoid membranes: an anatomical study. Laboratory investigation. Journal of Neurosurgery. 115 (1), 2011, 171-178.

[10]. Yad Ram Yadav, Vijay Parihar, SonjjayPande, HemantNamdev, and MoneetAgarwal. Endoscopic third ventriculostomy . J Neurosci Rural Pract. 3(2), 2012, 163-173.

[11]. Yasargil MG, Kasdaglis K, Jain KK, Weber HP. Anatomical observations of the subarachnoid cisterns of the brain during surgery. J Neurosurg 44, 1976, 298-302.

[12]. Zhang M, An PC. Liliequist's membrane is a fold of the arachnoid mater: Study using sheet plastination and scanning electron microscopy. Neurosurgery 47, 2000, 902-909. 